\section{Synthesis of Oligonucleotide Conjugates via Aqueous Diels-Alder Cycloaddition}

This unit describes in detail the preparation of $5^{\prime}$-labeled oligonucleotides via the aqueous Diels-Alder conjugation method. The unit is divided into three protocols: the first describing the preparation of the diene-amidite (see Basic Protocol 1); the second presenting the modification of oligonucleotides with the diene-amidite (see Basic Protocol 2); and the third describing the labeling of 5'-diene-modified oligonucleotides via Diels-Alder conjugation with TAMRA-5-maleimide (see Basic Protocol 3). All procedures are simple to perform with standard equipment and reagents.

CAUTION: All reactions must be performed in a well-ventilated fume hood. The use of proper laboratory precautions when handling all chemicals is mandatory. In particular, exposure of personnel to tert-butyldimethylsilyl chloride, bromine, $1,1^{\prime}$-carbonyldiimidazole, 2-cyanoethyl diisopropylchlorophosphoramidite, and $\mathrm{N}, \mathrm{N}$-diisopropylethylamine must be avoided.

\section{SYNTHESIS OF THE DIENE-AMIDITE}

The five-step synthesis route for the diene-amidite (S.7) employs commercially available 3-cyclohexene-1-methanol (S.1) as the starting material (Fig. 4.18.1). In the first step, the hydroxyl group of $\mathbf{S . 1}$ is protected by silylation with tert-butyldimethylsilyl chloride (TBDMS.Cl) to give the alkene S.2. In the next step, bromine is added. The resulting dibromide (S.3) is subjected to a bis-dehydrohalogenation reaction with potassium tert-butoxide to form the diene S.4. Removal of the TBDMS protecting group with strongly acidic Dowex resin and subsequent distillation of the crude product leads to pure 2,4-cyclohexadiene-1-methanol (S.5). Conjugation of S.5 to 6-amino-1-hexanol is accomplished in reaction with 1,1'-carbonyldiimidazole (CDI). The crude carbamate $\mathbf{S . 6}$ is purified by crystallization. Finally, S.6 is converted into the phosphoramidite S.7 by treatment with 2-cyanoethyl diisopropylchlorophosphoramidite and $\mathrm{N}, \mathrm{N}$-diisopropylethylamine (DIPEA). Purification of the crude product is performed by flash chromatography.

\section{Materials}

3-Cyclohexene-1-methanol (S.1; Aldrich)

Imidazole

Argon source

$N, N$-Dimethylformamide (DMF)

tert-Butyldimethylsilyl chloride (TBDMS.Cl; Aldrich)

Hexanes

Ethyl acetate (EtOAc)

TLC stain (see recipe)

Brine (saturated aqueous $\mathrm{NaCl}$ )

Magnesium sulfate $\left(\mathrm{MgSO}_{4}\right)$

Bromine

Dichloromethane $\left(\mathrm{CH}_{2} \mathrm{Cl}_{2}\right)$

$10 \%(\mathrm{w} / \mathrm{v})$ sodium thiosulfate $\left(\mathrm{Na}_{2} \mathrm{~S}_{2} \mathrm{O}_{3}\right)$

Aliquat 336 (tricaprylylmethylammonium chloride; Aldrich)

Tetrahydrofuran (THF)

Potassium tert-butoxide (Aldrich)

Saturated ammonium chloride $\left(\mathrm{NH}_{4} \mathrm{Cl}\right)$

Dowex 50WX4-50 strongly acidic ion-exchange resin (Aldrich)
BASIC

PROTOCOL 1
Synthesis of Modified

Oligonucleotides and Conjugates

4.18.1

Supplement 14 


$$
\overbrace{1} \mathrm{OH} \underset{\text { DMF, } 20 \mathrm{hr} \text {, quant. }}{\stackrel{\text { TBDMS.Cl/imidazole }}{\longrightarrow}} \overbrace{2}^{\text {OTBDMS }} \underset{1 \mathrm{hr}, 96 \%}{\stackrel{\mathrm{Br}_{2}, \mathrm{CH}_{2} \mathrm{Cl}_{2}}{\longrightarrow}}
$$

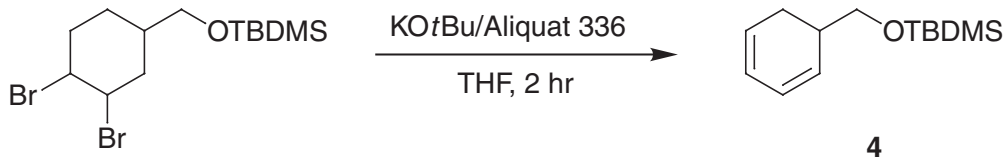

3
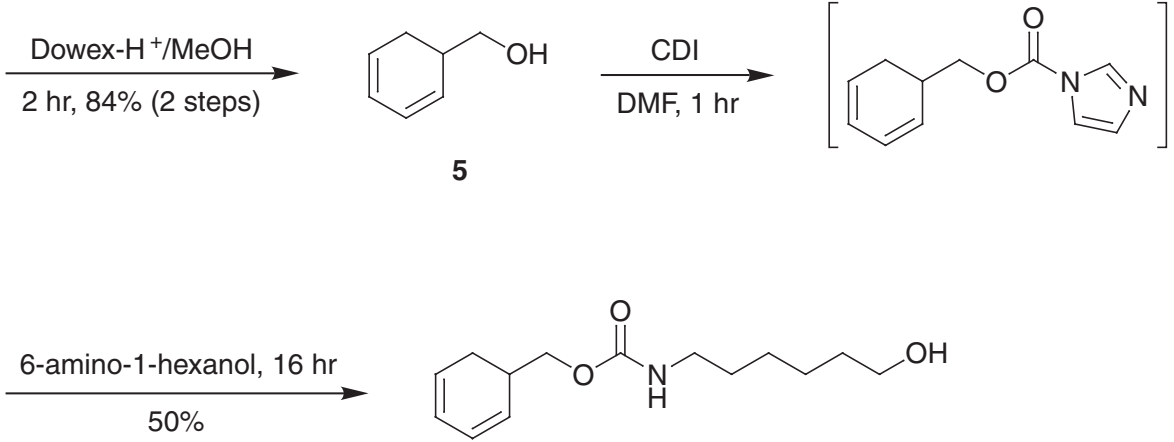<smiles>O=C(NCCCCCCO)OCC1C=CC=CC1</smiles>

6

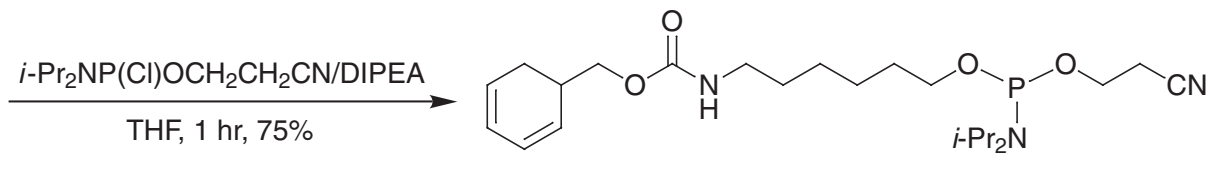

7

Figure 4.18.1 Preparation of diene-amidite (S.7). Abbreviations: Aliquat 336, tricaprylylmethylammonium chloride; CDI, 1,1'-carbonyldiimidazole; DIPEA, N,N-diisopropylethylamine; TBDMS.Cl, tert-butyldimethylsilyl chloride.

\section{Methanol}

1,1'-Carbonyldiimidazole (CDI; Aldrich)

6-Amino-1-hexanol (Aldrich)

$N, N$-Diisopropylethylamine (DIPEA; Aldrich)

2-Cyanoethyl diisopropylchlorophosphoramidite (Aldrich)

Saturated sodium bicarbonate $\left(\mathrm{NaHCO}_{3}\right)$

100- and 250-mL round-bottom flasks with outlet stopcock adapters for gas line

TLC plates: $7.5 \times 5-\mathrm{mm}$ silica gel $60 \mathrm{~F}_{254}$ precoated aluminum-backed TLC sheets (EM Science)

Synthesis of Oligonucleotide Conjugates via Diels-Alder Cycloaddition

\section{Heat gun}

1-L and 500-mL separatory funnels

Rotary evaporator equipped with a vacuum pump and vacuum controller Rubber septa 
10- and 50-mL vials

3- and 5-mL syringes with 2-in., 20-G stainless steel needles

Shaker

Short-path distillation apparatus (Aldrich)

Biotage Flash 40 chromatography system with Flash 40M silica cartridge

Additional reagents and equipment for TLC (APPENDIX $3 D)$ and flash chromatography (APPENDIX 3E)

\section{Perform silylation}

1. Weigh $2.78 \mathrm{~g}(24.8 \mathrm{mmol})$ of 3-cyclohexene-1-methanol (S.1) and $3.38 \mathrm{~g}(49.6 \mathrm{mmol})$ of imidazole into a 100-mL round-bottom flask equipped with a magnetic stir bar and an argon inlet. Apply an atmosphere of argon.

2. Add $25 \mathrm{~mL}$ of DMF and stir until all solids are dissolved.

3. Add $4.49 \mathrm{~g}(29.8 \mathrm{mmol})$ TBDMS. $\mathrm{Cl}$ to the reaction mixture and stir for $20 \mathrm{hr}$ at room temperature. Monitor reaction by TLC (APPENDIX 3D) using 100:1 (v/v) hexanes/ethyl acetate. Visualize spots by treating plate with TLC stain and heating with a heat gun.

TLC (hexanes/EtOAc 100:1): $R_{f}=0.05$ for starting material (S.1); 0.29 for TBDMS-ether (S.2).

\section{Perform aqueous workup of S.2}

4. Pour the reaction mixture into a 1-L separatory funnel. Add $250 \mathrm{~mL}$ of brine and extract the product with $150 \mathrm{~mL}$ of hexanes.

5. Repeat the extraction twice with $150 \mathrm{~mL}$ each of hexanes.

6. Combine the hexanes fractions and wash with $250 \mathrm{~mL}$ of brine.

7. After separation dry the organic phase over $\mathrm{MgSO}_{4}$.

8. Remove the $\mathrm{MgSO}_{4}$ by filtration and wash it twice, each time with $20 \mathrm{~mL}$ of hexanes.

9. Concentrate the combined filtrates under vacuum using a rotary evaporator equipped with a vacuum pump.

Typical yield of 4-(tert-butyldimethylsilyloxymethyl)cyclohex-1-ene (S.2): $5.62 \mathrm{~g}(100 \%)$ as colorless liquid. TLC (hexanes): $R_{f}=0.29 ;{ }^{13} \mathrm{C} \mathrm{NMR}\left(\mathrm{CDCl}_{3}\right): \delta$ 127.0, 126.2, 68.0, $36.3,28.2,26.0,25.7,25.3,24.8,18.4,-5.3$.

\section{Brominate alkene}

10. Weigh $5.62 \mathrm{~g}(24.8 \mathrm{mmol})$ of $\mathbf{S . 2}$ into a $250-\mathrm{mL}$ round-bottom flask equipped with a magnetic stir bar.

11. Add $50 \mathrm{~mL}$ of $\mathrm{CH}_{2} \mathrm{Cl}_{2}$, seal the flask with a rubber septum, and apply an atmosphere of argon. Dissolve the silyl ether (S.2) under stirring, then cool the solution with an ice bath to $0^{\circ} \mathrm{C}$.

12. In a separate $10-\mathrm{mL}$ vial, dissolve $1.3 \mathrm{~mL}(25.2 \mathrm{mmol})$ of bromine in $3 \mathrm{~mL}$ of $\mathrm{CH}_{2} \mathrm{Cl}_{2}$. Fill a 5-mL syringe with the bromine $/ \mathrm{CH}_{2} \mathrm{Cl}_{2}$ solution.

13. Attach the syringe to the flask (step 11) using a 20-G stainless steel needle to pierce the septum, and add the bromine solution dropwise under cooling.

At the beginning, the red color disappears immediately after addition. Finally, an orangered color remains.

14. After complete addition of the bromine solution, remove the ice bath and let the mixture stir for another $60 \mathrm{~min}$. Monitor by TLC (see step 3).

TLC (hexanes/EtOAc 100:1): $R_{f}=0.29$ for TBDMS-ether $(\boldsymbol{S . 2})$; 0.15 for dibromide $(\mathbf{S . 3})$.

Synthesis of Modified Oligonucleotides and Conjugates

4.18.3

Supplement 14 
Perform aqueous workup of $S .3$

15. Pour the reaction mixture into a 500-mL separatory funnel.

16. Rinse the flask with $150 \mathrm{~mL}$ of $\mathrm{CH}_{2} \mathrm{Cl}_{2}$ and add to the separatory funnel.

17. Wash the $\mathrm{CH}_{2} \mathrm{Cl}_{2}$ layer with $150 \mathrm{~mL}$ of $10 \% \mathrm{Na}_{2} \mathrm{~S}_{2} \mathrm{O}_{3}$, then with $150 \mathrm{~mL}$ of water.

18. Dry the organic phase over $\mathrm{MgSO}_{4}$.

19. Remove the $\mathrm{MgSO}_{4}$ by filtration and wash twice with $20 \mathrm{~mL}$ of $\mathrm{CH}_{2} \mathrm{Cl}_{2}$.

20. Concentrate the combined filtrates under vacuum in a rotary evaporator.

Typical yield of trans-1,2-dibromo-4-tert-butyldimethylsilyloxymethylcyclohexane (S.3): $9.19 \mathrm{~g}(96 \%)$ as yellow oil. TLC (hexanes/EtOAc 100:1): $R_{f}=0.15 .{ }^{13} \mathrm{C} \mathrm{NMR}\left(\mathrm{CDCl}_{3}\right): \delta$ $67.3,53.6,53.5,34.2,31.41,3.12,3.88,2.25,2.3,-5.4$.

\section{Perform bis-dehydrohalogenation}

21. Weigh $9.19 \mathrm{~g}(23.8 \mathrm{mmol})$ of $\mathbf{S . 3}$ and $0.20 \mathrm{~g}(0.5 \mathrm{mmol})$ of Aliquat 336 into a $250-\mathrm{mL}$ round-bottom flask equipped with a magnetic stir bar.

22. Add $70 \mathrm{~mL}$ of THF, seal the flask with an outlet stopcock adapter attached to an argon line, and apply an atmosphere of argon. Dissolve the dibromide (S.3) under stirring, then cool the solution with an ice bath to $0^{\circ} \mathrm{C}$.

23. Open the reaction flask by removing the adapter, add $5.88 \mathrm{~g}(52.4 \mathrm{mmol})$ of potassium tert-butoxide in one portion, seal the flask again with the adapter, and apply an atmosphere of argon (a yellow precipitate is immediately formed). Remove the ice bath after $5 \mathrm{~min}$ and continue stirring for $2 \mathrm{hr}$. Monitor by TLC.

TLC (hexanes/EtOAc 100:1): $R_{f}=0.15$ for dibromide (S.3); 0.25 for diene (S.4).

\section{Perform aqueous workup of S.4}

24. Pour the reaction mixture into a $500-\mathrm{mL}$ separatory funnel.

25. Rinse the flask with $100 \mathrm{~mL}$ of hexanes and add to the separatory funnel.

26. Wash the hexanes layer with $100 \mathrm{~mL}$ saturated $\mathrm{NH}_{4} \mathrm{Cl}$.

27. After separation, extract the aqueous phase with $50 \mathrm{~mL}$ of hexanes and wash the combined hexanes phases with $100 \mathrm{~mL}$ of water.

28. Dry the organic phase over $\mathrm{MgSO}_{4}$.

29. Remove the $\mathrm{MgSO}_{4}$ by filtration and wash it twice, each time with $20 \mathrm{~mL}$ of hexanes.

30. Concentrate the combined filtrates under vacuum at $40^{\circ} \mathrm{C}$, with pressure $\geq 180 \mathrm{mbar}$, in a rotary evaporator.

\section{Perform desilylation}

31. Weigh $8.60 \mathrm{~g}$ of Dowex 50WX4-50 into a 50-mL vial and wash it carefully three times, each time with $20 \mathrm{~mL}$ methanol.

After the third washing, the supernatant should be colorless.

32. Dissolve the $\mathbf{S . 4}$ residue from step 30 in $80 \mathrm{~mL}$ methanol, transfer it into a $250-\mathrm{mL}$ round-bottom flask, and add the washed Dowex 50WX4-50 resin.

33. Attach the flask to a shaker and shake the reaction mixture for $2 \mathrm{hr}$ at $200 \mathrm{rpm}$. Monitor by TLC using 3:1 (v/v) hexanes/ethyl acetate.

TLC (hexanes/EtOAc 3:1): $R_{f}=0.80$ for diene (S.4); 0.20 for diene-alcohol (S.5). 
Purify diene-alcohol S.5

34. Remove the ion-exchange resin by filtration and wash it twice with $20 \mathrm{~mL}$ methanol.

35. Concentrate the combined filtrates under vacuum at $40^{\circ} \mathrm{C}$, with pressure $\geq 180 \mathrm{mbar}$, in a rotary evaporator.

36. Transfer the residue into a round-bottom flask of appropriate size (5 or $10 \mathrm{~mL})$ and attach it to a short-path distillation apparatus. Distill the product under vacuum, collecting the fraction ranging from b.p. $47^{\circ} \mathrm{C}(2.2 \mathrm{mbar})$ to $50^{\circ} \mathrm{C}(1.7 \mathrm{mbar})$.

Typical yield of 2,4-cyclohexadiene-1-methanol (S.5): $2.20 \mathrm{~g}(84 \%)$ as colorless liquid. TLC (hexanes/EtOAc 3:1): $R_{f}=0.20 .{ }^{1} \mathrm{H} \mathrm{NMR}\left(\mathrm{CDCl}_{3}\right): \delta 5.98-5.62(\mathrm{~m}, 4 \mathrm{H}), 3.58(\mathrm{~d}, \mathrm{~J}$ $=5.9 \mathrm{~Hz}, 2 \mathrm{H}), 2.56-2.42(\mathrm{~m}, 1 \mathrm{H}), 2.37-2.05(\mathrm{~m}, 2 \mathrm{H}), 1.50(\mathrm{~s}, 1 \mathrm{H}) .{ }^{13} \mathrm{C} \mathrm{NMR}\left(\mathrm{CDCl}_{3}\right)$ : $\delta 126.9,125.4,125.0,123.6,64.6,35.5,24.9$.

\section{Conjugate diene-alcohol to 6-amino-1-hexanol}

37. Weigh $2.20 \mathrm{~g}(20.0 \mathrm{mmol})$ of $\mathbf{S . 5}$ into a $100-\mathrm{mL}$ round-bottom flask equipped with a magnetic stir bar.

38. Add $20 \mathrm{~mL}$ of DMF, seal the flask with an outlet stopcock adapter attached to an argon line, and apply an atmosphere of argon. Dissolve the diene (S.5) under stirring.

39. Open the reaction flask by removing the adapter, add $3.40 \mathrm{~g}(21.0 \mathrm{mmol})$ of CDI in one portion, seal the flask again with the adapter, and apply an atmosphere of argon. Continue stirring for $1 \mathrm{hr}$. Monitor by TLC using 1:1 (v/v) hexanes/ethyl acetate.

TLC (hexanes/EtOAc 1:1): $R_{f}=0.32$ for alcohol (S.5); 0.20 for the imidazolyl carbamate

40. Open the reaction flask by removing the adapter, add $2.34 \mathrm{~g}(20.0 \mathrm{mmol})$ of 6-amino-1-hexanol in one portion, seal the flask again with the adapter, and apply an atmosphere of argon. Continue stirring overnight. Monitor by TLC using 1:2 (v/v) hexanes/ethyl acetate.

$T L C$ (hexanes/EtOAc 1:2): $R_{f}=0.56$ for the imidazolyl carbamate; 0.44 for carbamate (S.6).

\section{Perform aqueous workup of carbamate S.6}

41. Concentrate the reaction mixture under vacuum in a rotary evaporator.

42. Dissolve the residue in $100 \mathrm{~mL}$ of $\mathrm{CH}_{2} \mathrm{Cl}_{2}$ and transfer the solution into a $250-\mathrm{mL}$ separatory funnel.

43. Wash the $\mathrm{CH}_{2} \mathrm{Cl}_{2}$ layer twice, each time with $70 \mathrm{~mL}$ of water.

44. After separation, dry the organic phase over $\mathrm{MgSO}_{4}$.

45. Remove the $\mathrm{MgSO}_{4}$ by filtration and wash it twice, each time with $10 \mathrm{~mL}$ of $\mathrm{CH}_{2} \mathrm{Cl}_{2}$.

46. Concentrate the combined filtrates under vacuum in a rotary evaporator.

47. Recrystallize the crude product from $\mathrm{CH}_{2} \mathrm{Cl}_{2}$.

Typical yield of 6-(cyclohexa-1,3-dien-5-yl)methylcarbamoylhexan-1-ol (S.6): $2.53 \mathrm{~g}$ $(50 \%)$ as colorless crystals, m.p. $65^{\circ} \mathrm{C} . \mathrm{TLC}$ (hexanes/EtOAc 1:2): $R_{f}=0.44 .{ }^{1} \mathrm{H} \mathrm{NMR}(300$ $\left.\mathrm{MHz}, \mathrm{CD}_{3} \mathrm{CN}\right): \delta 6.01-5.96(\mathrm{~m}, 1 \mathrm{H}), 5.94-5.89(\mathrm{~m}, 1 \mathrm{H}), 5.86-5.78(\mathrm{~m}, 1 \mathrm{H}), 5.72-5.67(\mathrm{~m}$, $1 \mathrm{H}), 5.51(\mathrm{bs}, 1 \mathrm{H}), 3.96-3.89(\mathrm{~m}, 2 \mathrm{H}), 3.49(q, J=5.6 \mathrm{~Hz}, 2 \mathrm{H}), 3.08(q, J=6.6 \mathrm{~Hz}, 2 \mathrm{H})$, 2.68-2.50(m, $1 H), 2.49(t, J=5.6 H z, 1 H), 2.31-2.21(\mathrm{~m}, 1 H), 2.15-2.02(\mathrm{~m}, 1 \mathrm{H}), 1.54-1.45$ (m, 4H), 1.40-1.26 (m, 4H). ${ }^{13} \mathrm{C} \mathrm{NMR}\left(75 \mathrm{MHz}, C D_{3} C N\right): \delta 156.8,127.0,126.0,125.6$, 125.0, 61.7, 61.5, 40.7, 33.0, 32.8, 29.9, 26.5, 25.5, 25.0. $M S(F A B): m / z 254[M+H]^{+}$. 
48. Weigh $2.53 \mathrm{~g}(10.0 \mathrm{mmol})$ of $\mathbf{S . 6}$ into an oven-dried $100-\mathrm{mL}$ round-bottom flask equipped with a magnetic stir bar.

49. Add $25 \mathrm{~mL}$ of dry THF and $2.6 \mathrm{~mL}$ ( $15 \mathrm{mmol}$ ) of DIPEA, seal the flask with a septum, and apply an atmosphere of argon. Dissolve the alcohol (S.6) under stirring.

50. Weigh $2.49 \mathrm{~g}(10.5 \mathrm{mmol})$ of 2-cyanoethyl diisopropylchlorophosphoramidite into a 3 -mL syringe.

51. Attach the syringe to the flask via the septum and add the chlorophosphoramidite dropwise. Rinse the syringe with $3 \mathrm{~mL}$ of dry THF and add this solution to the reaction mixture. Continue stirring for $1 \mathrm{hr}$. Monitor by TLC using ethyl acetate.

TLC (EtOAc): $R_{f}=0.50$ for carbamate (S.6); 0.83 for amidite (S.7).

\section{Perform aqueous work-up and purification of S.7}

52. Pour the reaction mixture into a $250-\mathrm{mL}$ separatory funnel.

53. Add $75 \mathrm{~mL}$ of $\mathrm{CH}_{2} \mathrm{Cl}_{2}$ and wash the organic layer three times with $75 \mathrm{~mL}$ saturated $\mathrm{NaHCO}_{3}$.

54. Dry the organic phase over $\mathrm{MgSO}_{4}$.

55. Remove the $\mathrm{MgSO}_{4}$ by filtration and wash it twice with $10 \mathrm{~mL} \mathrm{CH}_{2} \mathrm{Cl}_{2}$.

56. Concentrate the combined filtrates under vacuum in a rotary evaporator.

57. Dissolve the residue in $4 \mathrm{~mL}$ ethyl acetate and inject it on a Biotage Flash 40 chromatography system employing a Biotage Flash 40M silica gel cartridge equilibrated with ethyl acetate. Elute the product with ethyl acetate.

58. Concentrate the product-containing fractions under vacuum in a rotary evaporator. Dry the residue under high vacuum.

Typical yield of 1-[(2-cyanoethoxy)diisopropylaminophosphinyloxy]-6-(cyclohexa-1,3dien-5-yl)methylcarbamoylhexane (S.7): $3.40 \mathrm{~g}$ (75\%) as colorless oil. TLC (EtOAc): $R_{f}$ $=0.83 .{ }^{1} \mathrm{HNMR}\left(\mathrm{CD}_{3} \mathrm{CN}\right): \delta 6.01-5.87(\mathrm{~m}, 2 \mathrm{H}), 5.83-5.77(\mathrm{~m}, \mathrm{lH}), 5.71(\mathrm{~m}, 1 \mathrm{H}), 5.52(\mathrm{bs}$, $1 \mathrm{H})$, 3.97-3.89 (m, $2 \mathrm{H}), 3.89-3.70(\mathrm{~m}, 2 \mathrm{H}), 3.70-3.56(\mathrm{~m}, 4 \mathrm{H}), 3.07(q, J=6.6 \mathrm{~Hz}, 2 \mathrm{H})$, 2.70-2.53 $(\mathrm{m}, 1 \mathrm{H}), 2.66(\mathrm{t}, \mathrm{J}=5.9 \mathrm{~Hz}, 2 \mathrm{H}), 2.31-2.15(\mathrm{~m}, 1 \mathrm{H}), 2.15-2.01(\mathrm{~m}, 1 \mathrm{H}), 1.64-1.26$ (m, 8H), $1.20(\mathrm{~s}, 3 \mathrm{H}), 1.19,(\mathrm{~s}, 3 \mathrm{H}), 1.18(\mathrm{~s}, 3 \mathrm{H}), 1.17(\mathrm{~s}, 3 \mathrm{H}) .{ }^{13} \mathrm{CNMR}\left(\mathrm{CD}_{3} \mathrm{CN}\right): \delta 156.7$, 127.0, 125.8, 125.3, 124.0, 118.9, 65.7, 63.6, 63.4, 58.6, 58.4, 43.1, 42.9, 40.7, 33.2, 31.2, 31.1, 29.9, 26.3, 25.6, 25.0, 24.2, 24.1, 20.4, 20.3. ${ }^{31} P N M R\left(C D_{3} C N\right): \delta$ 148.0. MS (FAB): $\mathrm{m} / z$. $455[\mathrm{M}+\mathrm{H}]^{+}$. Anal. calcd. for $\mathrm{C}_{23} \mathrm{H}_{40} \mathrm{~N}_{3} \mathrm{O}_{4} \mathrm{P}: \mathrm{C}, 60.91 ; \mathrm{H}, 8.89 ; \mathrm{N}$, 9.26; found: $\mathrm{C}$, 60.55; H, 9.23; N, 9.10. RP-HPLC: $R_{t}=12.67 \mathrm{~min}$; Waters Nova-Pak C18 column (4 $\mu \mathrm{m}$, $3.9 \times 150 \mathrm{~mm}$ ) eluting with a linear gradient from $40 \%$ to $100 \%$ A (solvent A, acetonitrile; solvent $B, 250 \mathrm{mM}$ triethylammonium acetate, $\mathrm{pH}$ 6.5) in $15 \mathrm{~min}$ with a flow rate of 1 $\mathrm{mL} / \mathrm{min}$; $U V$ detection performed at $\lambda=254 \mathrm{~nm}$. 


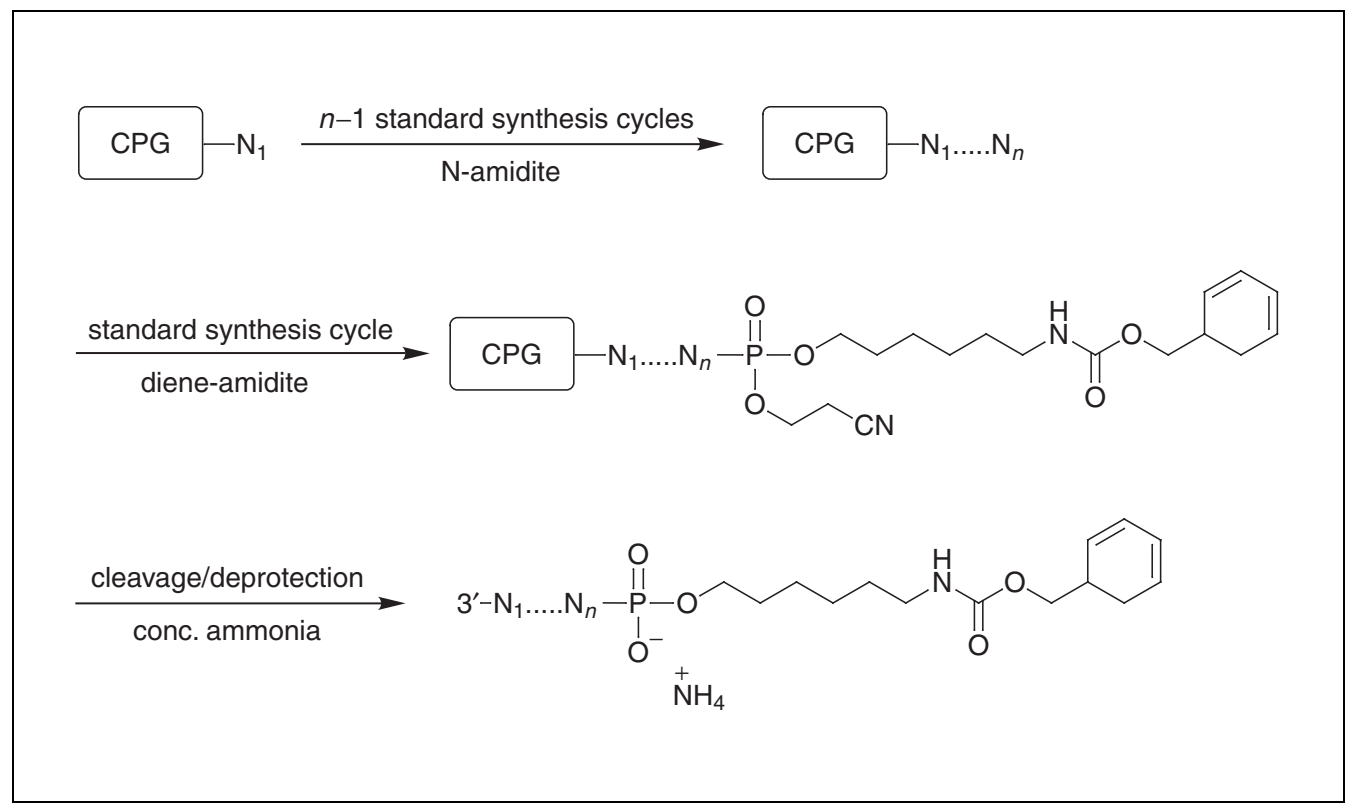

Figure 4.18.2 Synthesis of diene-modified oligonucleotides. Standard synthesis cycle: deblocking (deblock solution); coupling ( $\mathrm{N}$-amidite/DCl); capping (Cap A and B solutions); oxidation (oxidizer solution). N-amidite: standard dT, dC(bz), dA(bz), dG(ib) phosphoramidites.

SYNTHESIS OF 5'-DIENE-MODIFIED OLIGONUCLEOTIDES

This protocol describes the setup and steps required for automated assembly of 5'-dienemodified oligonucleotides on a 1- $\mu \mathrm{mol}$ scale. The protocol was developed for the Expedite 8909 DNA synthesizer, but can easily be adapted to other automated DNA synthesizers. The reactions carried out in each cycle are shown in Figure 4.18.2. For further details on automated oligonucleotide synthesis, see APPENDIX $3 C$.

The instrument manufacturer's synthesis protocol in DMTr-ON mode is applied for the assembly of the oligonucleotide with standard reagents for solid-phase oligonucleotide synthesis. The diene-amidite (S.7) is employed at a concentration of $50 \mathrm{mg} / \mathrm{mL}$ in acetonitrile in the last coupling cycle. After completion of the synthesis, the oligonucleotide is cleaved from the CPG support and subsequently deprotected by treatment with concentrated ammonium hydroxide. Desalting of the crude oligonucleotide is accomplished by alcohol precipitation.

\section{Materials}

Dry acetonitrile (DNA synthesis grade; $\mathrm{H}_{2} \mathrm{O}$ content $<30 \mu \mathrm{g} / \mathrm{mL}$ )

Deblock solution: trichloroacetic acid (TCA) in dichloromethane (Proligo)

Cap A solution: acetic anhydride in tetrahydrofuran (Proligo)

Cap B solution: 1-methylimidazole in tetrahydrofuran/pyridine (Proligo)

Oxidizer solution: iodine in tetrahydrofuran/water/pyridine (Proligo)

Activator: $0.25 \mathrm{M}$ 4,5-dicyanoimidazole (DCI) in acetonitrile (Proligo)

$50 \mathrm{mg} / \mathrm{mL}$ standard phosphoramidites [dT, dC(bz), dA(bz), and dG(ib); Proligo] in dry acetonitrile

$50 \mathrm{mg} / \mathrm{mL}$ diene-amidite (S.7; see Basic Protocol 1) in dry acetonitrile

Helium source

Concentrated ammonium hydroxide $\left(\mathrm{NH}_{4} \mathrm{OH}\right)$

$3 \mathrm{M}$ sodium acetate (APPENDIX 2A)

Isopropanol

$70 \%(\mathrm{v} / \mathrm{v})$ ethanol

Synthesis of

Modified

Oligonucleotides and Conjugates

4.18.7

Supplement 15 
Automated DNA synthesizer (e.g., Expedite 8909, PerSeptive Biosystems)

Synthesis column for 1- $\mu$ mol scale (Proligo): controlled-pore glass (CPG; $500 \AA$ for $<50$-mers, $1000 \AA$ for $\geq 50$-mers)

Heating block

Speedvac evaporator

Additional reagents and equipment for quantitating oligonucleotides by $\mathrm{OD}_{260}$ measurement (UNIT 10.3)

\section{Perform automated synthesis}

1. Install the bottles with all reagents (acetonitrile, deblock solution, cap A and B solutions, oxidizer solution, activator solution), phosphoramidite solutions [dT, $\mathrm{dC}(\mathrm{bz}), \mathrm{dA}(\mathrm{bz})$, and $\mathrm{dG}(\mathrm{ib})]$, and diene-amidite $\mathbf{S . 7}$ in an automated DNA sythesizer according to the manufacturer's instructions (also see APPENDIX $3 C$ ). Flush with helium and prime the fluidics system three times.

2. Use the sequence editor to enter a new sequence or edit an existing sequence for synthesis.

3. Load the appropriate synthesis column for $1-\mu \mathrm{mol}$ scale.

4. Choose the DMTr-ON option in the setup menu and perform the synthesis.

The standard synthesis cycle is applied in the last cycle for the diene-amidite (S.7) coupling. Cycle steps are listed in Table 4.18.1.

5. Remove the synthesis column from the instrument.

6. Cleave the oligonucleotide from the solid support in the column by treatment with 1 $\mathrm{mL}$ concentrated ammonium hydroxide for $30 \mathrm{~min}$ at room temperature.

7. Collect the ammonia solution containing the oligonucleotide into a screw-cap tube and deprotect the oligonucleotide by heating in a heating block at $55^{\circ} \mathrm{C}$ for $8 \mathrm{hr}$ or overnight.

8. Dry the deprotected oligonucleotide in a Speedvac evaporator.

\section{Desalt oligonucleotides}

9. Dissolve $\sim 100 \mathrm{OD}_{260}$ units of crude oligonucleotide in $100 \mu \mathrm{L}$ of deionized water.

10. Add $11 \mu \mathrm{L}$ of $3 \mathrm{M}$ sodium acetate solution and mix.

11. Add $333 \mu \mathrm{L}$ of isopropanol, then vortex.

12. Incubate overnight at room temperature.

13. Microcentrifuge $10 \mathrm{~min}$ at maximum speed $(\geq 10,000 \times g)$, room temperature.

14. Remove the supernatant and discard; avoid disturbing the pellet.

15. Add $300 \mu \mathrm{L}$ of $70 \%$ ethanol, mix briefly, and place in a freezer at $-20^{\circ} \mathrm{C}$ for $2 \mathrm{hr}$.

16. Microcentrifuge $5 \mathrm{~min}$ at maximum speed $(\geq 10,000 \times g)$, room temperature.

17. Remove the supernatant and discard.

18. Evaporate pellet to dryness in a Speedvac evaporator.

19. Quantify the oligonucleotide by $\mathrm{OD}_{260}$ measurement (UNIT 10.3).

Synthesis of Oligonucleotide

Conjugates via Diels-Alder

Cycloaddition

4.18.8 
Table 4.18.1 Standard Expedite 1- $\mu \mathrm{mol}$ DNA Synthesis Protocol Applied for Synthesis of Diene-Modified Oligonucleotides using Diene-Amidite (S.7).

\begin{tabular}{|c|c|c|c|c|c|}
\hline Operation & Function & Mode & Amount & Time (sec) & Description \\
\hline \multicolumn{6}{|l|}{ Deblocking } \\
\hline 144 & $\begin{array}{l}\text { Index Fract. } \\
\text { Coll. }\end{array}$ & NA & 1 & 0 & Event out ON \\
\hline 0 & Default & WAIT & 0 & 1.5 & Wait \\
\hline 141 & $\begin{array}{l}\text { Trityl Mon. } \\
\text { On/Off }\end{array}$ & NA & 1 & 1 & $\begin{array}{l}\text { START data } \\
\text { collection }\end{array}$ \\
\hline 16 & Dblk & PULSE & 10 & 0 & Dblk to column \\
\hline 16 & Dblk & PULSE & 50 & 49 & Deblock \\
\hline 38 & $\begin{array}{l}\text { Diverted Wsh } \\
\text { A }\end{array}$ & PULSE & 40 & 0 & $\begin{array}{l}\text { Flush system with } \\
\text { Wsh A }\end{array}$ \\
\hline 141 & $\begin{array}{l}\text { Trityl Mon. } \\
\text { On/Off }\end{array}$ & NA & 0 & 1 & STOP data collection \\
\hline 38 & $\begin{array}{l}\text { Diverted Wsh } \\
\text { A }\end{array}$ & PULSE & 40 & 0 & $\begin{array}{l}\text { Flush system with } \\
\text { Wsh A }\end{array}$ \\
\hline 144 & $\begin{array}{l}\text { Index Fract. } \\
\text { Coll. }\end{array}$ & NA & 2 & 0 & Event out OFF \\
\hline \multicolumn{6}{|l|}{ Coupling } \\
\hline 1 & Wsh & PULSE & 5 & 0 & $\begin{array}{l}\text { Flush system with } \\
\text { Wsh }\end{array}$ \\
\hline 2 & Act & PULSE & 5 & 0 & $\begin{array}{l}\text { Flush system with } \\
\text { Act }\end{array}$ \\
\hline 22 & S.7 + Act & PULSE & 6 & 0 & $\begin{array}{l}\text { Monomer + Act to } \\
\text { column }\end{array}$ \\
\hline 22 & S.7 + Act & PULSE & 1 & 8 & Couple monomer \\
\hline 2 & Act & PULSE & 4 & 32 & Couple monomer \\
\hline 1 & Wsh & PULSE & 7 & 56 & Couple monomer \\
\hline 1 & Wsh & PULSE & 8 & 0 & $\begin{array}{l}\text { Flush system with } \\
\text { Wsh }\end{array}$ \\
\hline \multicolumn{6}{|l|}{ Capping } \\
\hline 12 & Wsh A & PULSE & 20 & 0 & $\begin{array}{l}\text { Flush system with } \\
\text { Wsh A }\end{array}$ \\
\hline 13 & Caps & PULSE & 8 & 0 & Caps to column \\
\hline 12 & Wsh A & PULSE & 6 & 15 & Cap \\
\hline 12 & Wsh A & PULSE & 14 & 0 & $\begin{array}{l}\text { Flush system with } \\
\text { Wsh A }\end{array}$ \\
\hline \multicolumn{6}{|l|}{ Oxidizing } \\
\hline 15 & Ox & PULSE & 15 & 0 & Ox to column \\
\hline 12 & Wsh A & PULSE & 15 & 0 & $\begin{array}{l}\text { Flush system with } \\
\text { Wsh A }\end{array}$ \\
\hline \multicolumn{6}{|l|}{ Capping } \\
\hline 13 & Caps & PULSE & 7 & 0 & Caps to column \\
\hline 12 & Wsh A & PULSE & 30 & 0 & End of cycle wash \\
\hline
\end{tabular}

Synthesis of

Modified

Oligonucleotides

and Conjugates

4.18.9 
This protocol describes the conjugation of TAMRA-5-maleimide to a diene-modified oligonucleotide via aqueous Diels-Alder cycloaddition (Fig. 4.18.3). The crude 5'-dienemodified oligonucleotide is dissolved in sodium acetate buffer, $\mathrm{pH} 4.5$, and treated with a 10-fold excess of TAMRA-5-maleimide. The mixture is heated at $60^{\circ} \mathrm{C}$ for $4 \mathrm{hr}$. Excess dye is removed by size-exclusion chromatography employing NAP-5 columns. The labeled oligonucleotides obtained can be purified by high-performance liquid chromatography (HPLC; UNIT 10.5) or polyacrylamide gel electrophoresis (PAGE; UNIT 10.4).

\section{Materials}

Diene-modified oligonucleotide (see Basic Protocol 2)

$100 \mathrm{mM}$ sodium acetate buffer, $\mathrm{pH} 4.5$ (APPENDIX 2A)

40 mM TAMRA-5-maleimide solution: 5.0 mg TAMRA-5-maleimide (Molecular Probes) in $268 \mu \mathrm{L}$ dimethylformamide (DMF)

Heating block

NAP-5 columns (Amersham Pharmacia Biotech)

Speedvac evaporator

Additional reagents and equipment for quantitating oligonucleotides by $\mathrm{OD}_{260}$ measurement (UNIT 10.3)

\section{Label diene-modified oligonucleotide}

1. Prepare a $1 \mathrm{mM}$ stock solution of the diene-modified oligonucleotide in deionized water.

Calculations are based on the $O D_{260}$ readings obtained (see Basic Protocol 2, step 19) and the calculated extinction coefficient of the oligonucleotide (UNIT 10.3).

Synthesis of Oligonucleotide

Conjugates via Diels-Alder Cycloaddition

4.18.10
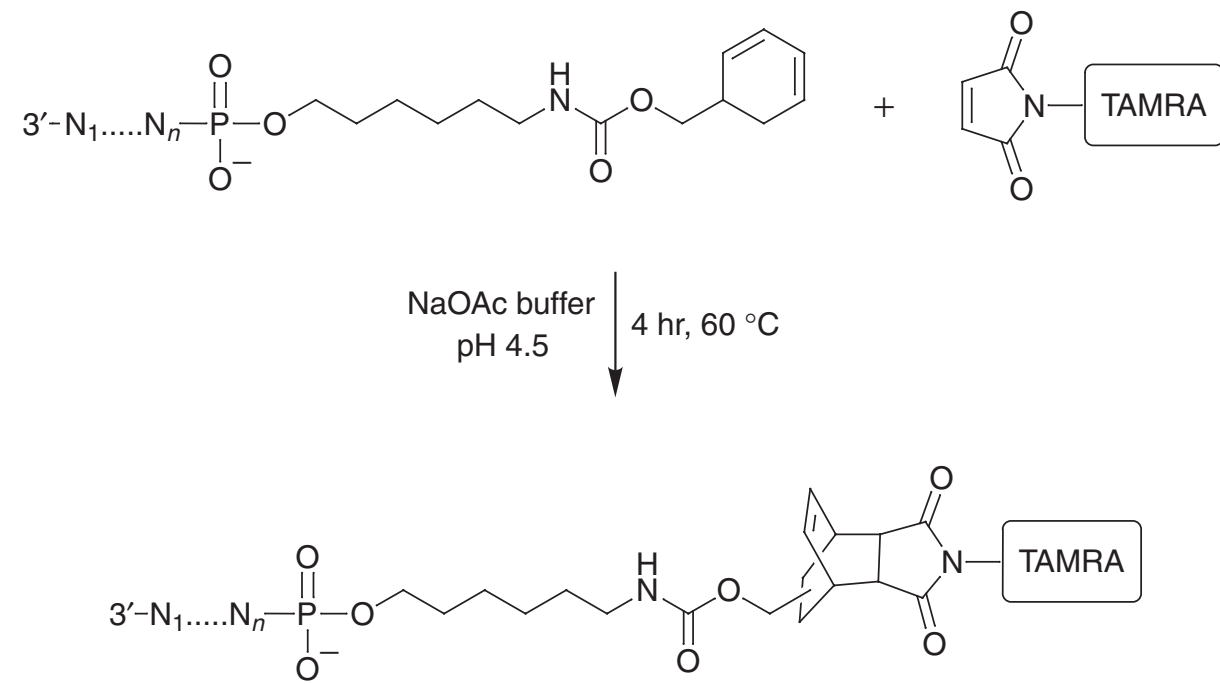

Figure 4.18.3 Labeling of diene-modified oligonucleotide with TAMRA-5-maleimide via aqueous Diels-Alder cycloaddition. 
2. In a $1.5-\mathrm{mL}$ microcentrifuge tube, prepare a mixture of:

$20 \mu \mathrm{L} 1 \mathrm{mM}$ diene-modified oligonucleotide (20 nmol)

$50 \mu \mathrm{L} 100 \mathrm{mM}$ sodium acetate buffer, $\mathrm{pH} 4.5$

$25 \mu \mathrm{L}$ deionized water

$5 \mu \mathrm{L} 40 \mathrm{mM}$ TAMRA-5-maleimide solution.

3. Incubate the mixture for $4 \mathrm{hr}$ at $60^{\circ} \mathrm{C}$ in a heating block. If desired, store mixture up to 2 to 4 weeks at $-20^{\circ} \mathrm{C}$.

\section{Remove excess dye by size-exclusion chromatography}

4. Remove the top of the NAP-5 column and discard the preservative solution into a waste container. Remove the bottom cap.

5. Equilibrate the NAP-5 column with $10 \mathrm{~mL}$ of deionized water.

6. Load $100 \mu \mathrm{L}$ of the labeling solution and allow it to enter the NAP-5 gel bed completely.

7. Load $400 \mu \mathrm{L}$ of deionized water; discard the eluate.

8. Elute twice, each time with $500 \mu \mathrm{L}$ of deionized water, and collect $500-\mu \mathrm{L}$ fractions in separate vials.

9. Identify product-containing fractions by $\mathrm{OD}_{260}$ measurement (UNIT 10.3).

10. Combine the product-containing fractions and evaporate to dryness in a Speedvac evaporator.

11. Optional: Purify crude oligonucleotide by RP-HPLC (UNIT 10.5) or PAGE (UNIT 10.4).

\section{REAGENTS AND SOLUTIONS}

Use deionized, distilled water in all recipes and protocol steps. For common stock solutions, see APPENDIX 2A; for suppliers, see SUPPLIERS APPENDIX.

\section{TLC stain}

Solution A: Weigh $0.2 \mathrm{~g}$ of 3-methoxyphenol (Aldrich) into a 250-mL beaker and add absolute ethanol to make $100 \mathrm{~g}$ of solution $(0.2 \% \mathrm{w} / \mathrm{w}$ final $)$.

Solution B: Add $5.3 \mathrm{~mL}$ concentrated sulfuric acid $\left(\mathrm{H}_{2} \mathrm{SO}_{4}\right)$ to a $250-\mathrm{mL}$ beaker containing $\sim 50 \mathrm{~mL}$ of absolute ethanol. Add ethanol to make $100 \mathrm{~mL}\left(1 \mathrm{M} \mathrm{H}_{2} \mathrm{SO}_{4}\right.$ final).

TLC stain: In a $250-\mathrm{mL}$ screw-cap vial, mix equal volumes of solutions A and B (usually $50 \mathrm{~mL}$ ). Prepare fresh.

CAUTION: Sulfuric acid is corrosive. Avoid skin and eye contact. Addition of the acid to ethanol is exothermic.

\section{COMMENTARY}

\section{Background Information}

The chemical synthesis of modified oligonucleotides is of increasing interest for studying biological processes in vivo and in vitro, in particular for diagnostic applications. Oligonucleotides are modified to prepare conjugates with reporter groups such as fluorophores or biotin, ligands for radioactive labeling, peptides, enzymes, antibodies, and carbohy- drates (Goodchild, 1990). Other applications require the attachment of oligonucleotides to surfaces, e.g., to produce microarrays (Bowtell and Sambrook, 2002) or to conjugate oligonucleotides to nanoparticles (Letsinger et al., 2000). A number of strategies have been applied to chemically modify oligonucleotides at the $3^{\prime}$ and/or $5^{\prime}$ terminus (UNITS 4.2, 4.3, 4.5, \& 4.6) or in the middle of the sequence. For $3^{\prime}$-modi-
Synthesis of Modified Oligonucleotides and Conjugates

4.18.11

Supplement 14 
fication, a branched linker is attached to the solid support employed for oligonucleotide synthesis. The linker either comprises a functional group for postsynthetic modification reactions or an attached reporter group or ligand that alleviates the need for postsynthetic modifications (UNITS 4.5 \& 4.6). Functionalized nucleoside building blocks are used to incorporate a modification in the middle of the sequence (Telser et al., 1989) or at the $5^{\prime}$ terminus (Smith et al., 1985). For 5'-modification, a non-nucleosidic phosphoramidite such as fluorochrome amidite or a biotin-functionalized amidite can be coupled to the oligonucleotide in the last synthesis cycle (UNITS 4.2 \& 4.3). Many fluorochrome-phosphoramidites and other amidites containing reporter groups of haptens are commercially available to allow on-support labeling.

As an alternative method, the phosphoramidite employed in the last synthesis cy- cle can contain a protected functional group. After its deprotection, the functional group is available for postsynthetic conjugation to a modifier containing the corresponding functionality for attachment (UNIT 4.2). Examples of standard conjugation methods are given in Figure 4.18.4. The Diels-Alder conjugation method (Hill et al., 2001) extends the portfolio of conjugation chemistries, as it contains some unique features.

(1) The method is applicable for conjugation reactions in aqueous media and therefore allows postsynthetic labeling of oligonucleotides.

(2) Protection of the functional group is not necessary, as the diene moiety is stable under the standard synthesis and deprotection conditions employed for solid-phase oligonucleotide synthesis.

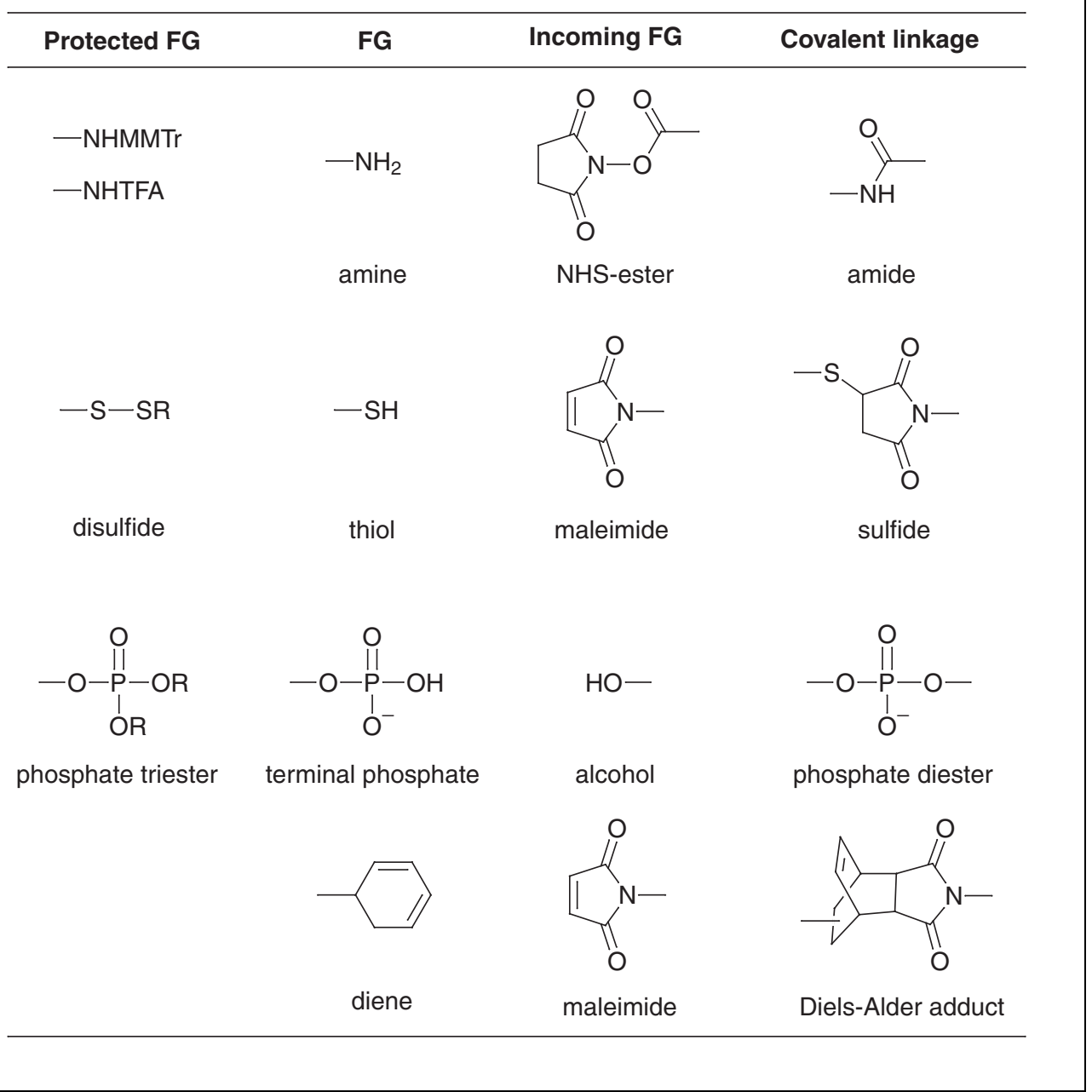

Figure 4.18.4 Common oligonucleotide conjugation methods. Abbreviations: FG, functional group; MMTr, 4-monomethoxytrityl; TFA, 2,2,2-trifluoroacetyl.
Synthesis of Oligonucleotide Conjugates via Diels-Alder Cycloaddition

4.18.12 
(3) The Diels-Alder conjugation reaction is fast and selective for dienophiles, such as maleimides.

(4) The method is orthogonal to other common methods (see Fig. 4.18.4) and therefore allows combination with other functionalities (e.g., amines) to prepare dual-labeled probes in one pot.

Basic Protocol 3 allows for the conjugation of diene-modified oligonucleotides to any substrate containing maleimides or other suitable dienophiles and allows the preparation of modified oligonucleotides used in the spectrum of biological applications.

\section{Critical Parameters}

\section{Synthesis of diene-alcohol}

The synthesis of the diene-alcohol $\mathbf{S . 5}$ is straightforward and can be conveniently performed on a larger scale. It is not necessary to purify intermediates $\mathbf{S . 2}$ to $\mathbf{S . 4}$, as compound S.5 can be satisfactorily purified by fractional distillation. For successful performance of the bis-dehydrohalogenation, it is crucial to use fresh potassium tert-butoxide and to use anhydrous conditions; otherwise, prolonged reaction times or incomplete conversion will be observed. If the reaction is not complete after the time given in the protocol, an additional portion of potassium tert-butoxide ( $10 \%$ of the initial amount) should be added and the reaction mixture stirred for another hour. Compounds $\mathbf{S . 4}$ and $\mathbf{S . 5}$ appear to be volatile liquids. After evaporation of the organic phases containing these volatile intermediates, drying under high vacuum should be avoided.

\section{Purification and storage of diene-amidite}

If wet silica gel is used for the flash chromatography of diene-amidite S.7, the formation of byproducts may be observed. Equilibration of the column employing a $1 \%$ solution of triethylamine in EtOAc, instead of EtOAc alone, helps to buffer the acidic silica gel. Subsequently, the column should be treated with EtOAc to replace the triethylamine solution. After purification, the amidite (S.7) should be dried under high vacuum and stored under dry argon in a refrigerator at $4^{\circ} \mathrm{C}$. It is advantageous to distribute the amidite to appropriate clean, dry synthesizer bottles immediately after preparation in order to avoid repeated opening of the amidite container. The bottles should be flushed with argon and sealed.

\section{Oligonucleotide synthesis}

The synthesizer used for oligonucleotide synthesis should be operated and maintained according to the manufacturer's instructions. It is crucial to use appropriate solvents and reagents and to prime all the lines carefully prior to synthesis. A freshly prepared solution of diene-amidite (S.7) should be used. It is not necessary to prolong the coupling time for the final diene-amidite coupling compared to coupling of standard amidites.

\section{Diels-Alder cycloaddition reaction}

The reaction conditions for the Diels-Alder conjugation reaction have given the best labeling results. For sensitive substrates, it could be desirable to carry out the Diels-Alder conjugation under different reaction conditions, such as lower temperature or higher $\mathrm{pH}$. Successful conjugation may only be possible in exchange for a lower yield. Limitations are: (1) fast hydrolysis of maleimides at $\mathrm{pH}>8$, (2) decreased reaction rates at temperatures $<35^{\circ} \mathrm{C}$, and (3) the requirement that DMF content not exceed $20 \%$. Purification of crude oligonucleotide conjugates can be performed by standard methods such as reversed-phase high-performance liquid chromatography (RP-HPLC; UNIT 10.5) or polyacrylamide gel elctrophoresis (PAGE; UNIT 10.4).

\section{Anticipated Results}

By applying the methods in this unit and observing the critical parameters, it is possible to prepare the diene-amidite (S.7) at a $30 \%$ overall yield, with a purity of $\geq 98 \%$, determined by RP-HPLC and ${ }^{31}$ P NMR analysis (see Basic Protocol 2). Diene-functionalization of oligonucleotides employing pure phosphoramidite (S.7) usually provides coupling efficiencies $>99 \%$. The conjugation of dienefunctionalized oligonucleotides to maleimides typically proceeds with efficiencies $>80 \%$.

\section{Time Considerations}

The preparation of diene-amidite (S.7) takes $\sim 2$ weeks, if the scale given in the protocol is applied. The time for the assembly of a 5 '-dienemodified oligonucleotide (synthesis of a 20mer on $1-\mu \mathrm{mol}$ scale), including deprotection and desalting, takes $\sim 3$ days. The conjugation reaction, including size-exclusion chromatography, typically requires 2 days.
Synthesis of Modified Oligonucleotides and Conjugates

4.18.13 


\section{Literature Cited}

Bowtell, D. and Sambrook, J. (eds.) 2002. DNA Microarrays: A Molecular Cloning Manual. Cold Spring Harbor Laboratory Press, Cold Spring Harbor, N.Y.

Goodchild, J. 1990. Conjugates of oligonucleotides and modified oligonucleotides: A review of their synthesis and properties. Bioconjugate Chem. 1:165-187.

Hill, K.W., Taunton-Rigby, J., Carter, J.D., Kropp, E., Vagle, K., Pieken, W., McGee, D.P.C., Husar, G., Leuck, M., Anziano, D., and Sebesta, D.P. 2001. Diels-Alder bioconjugation of dienemodified oligonucleotides. J. Org. Chem. 66:5352-5358.

Letsinger, R.L., Elghanian, R., Biswanadham, G., and Mirkin, C. 2000. Use of a steroid cyclic disulfide anchor in constructing gold nanoparticle-oligonucleotide conjugates. Bioconjugate Chem. 11:289-291.
Smith, L.M., Fung, S., Hunkapiller, M.W., Hunkapiller, T.J., and Hoo, L.E. 1985. The synthesis of oligonucleotides containing an aliphatic amino group at the $5^{\prime}$ terminus: Synthesis of fluorescent DNA primers for use in DNA sequence analysis. Nucl. Acids Res. 13:2399-2412.

Telser, J., Cruickshank, K.A., Morrison, L.E., and Netzel, T.L. 1989. Synthesis and characterization of DNA oligomers and duplexes containing covalently attached molecular labels: Comparison of biotin, fluorescein, and pyrene labels by thermodynamic and optical spectroscopic measurements. J. Am. Chem. Soc. 111:6966-6976.

Contributed by Michael Leuck and Andreas Wolter

Proligo LLC

Boulder, Colorado 